\title{
A FOTOGRAFIA 360 GRAUS COMO FERRAMENTA DE SUPORTE À MODELAGEM DE AS BUILT
}

\section{THE 360-DEGREES PHOTOGRAPHY AS A SUPPORT TOOL TO AS BUILT MODELING}

\author{
Gabriel George Grosskopf ${ }^{1}$ \\ Universidade Federal de Santa Catarina, Florianópolis, SC, Brasil, gabreorge@gmail.com \\ Yasmin Sarquis Herden ${ }^{2}$ \\ Universidade Federal de Santa Catarina, Florianópolis, SC, Brasil, yasminherden@gmail.com \\ Rafael Fernandes Teixeira Silva ${ }^{3}$ \\ Secretaria de Estado do Planejamento de Santa Catarina, Florianópolis, SC, Brasil, rafaelfernandes@spg.sc.gov.br \\ Fernanda Fernandes Marchiori 4 \\ Universidade Federal de Santa Catarina, Florianópolis, SC, Brasil, fernanda.marchiori@ufsc.br
}

\begin{abstract}
Resumo
Considerando a pertinência do as built para reformas e manutenções e a ascensão de novas tecnologias na Indústria 4.0, foi analisada a contribuição de fotografias 360 graus nas etapas de levantamento de dados e validação de informações para modelagem desse documento, comparando-a com a fotografia tradicional usualmente utilizada. Partindo-se de pesquisa empírica em campo, foram modelados dois as built em software BIM do processo de reforma da edificação da Fundação Nova Vida, em Florianópolis (SC), dedicada à assistência social. Com os as built pré-reforma e pós-reforma foi possível comparar as duas modalidades: fotografias tradicionais na etapa pré-reforma e fotografias com lente esférica 360 graus na etapa pós-reforma. Parâmetros como quantidade de informações contidas e tamanho dos conjuntos de arquivos fotográficos gerados foram considerados no estudo. A fotografia 360 graus apresentou mais dados e maior área de abrangência, reduzindo a quantidade de arquivos gerados e o tamanho do conjunto de arquivos armazenados. A fotografia tradicional, por envolver a tomada de decisão sobre o que registrar, demanda tempo extra em levantamentos em campo, enquanto a fotografia 360 graus faz um registro global. A fotografia 360 graus mostrou-se mais eficaz do que a tradicional, proporcionando maior agilidade na coleta e conferência de dados para a modelagem BIM.
\end{abstract}

Palavras-chave: Fotografia 360 graus. Fotografia imersiva. As built. Reforma. BIM.

\begin{abstract}
Considering the relevance of 'as built' for renovations and maintenance and the rising of new technologies in the 4.0 Industry, the contribution of 360-degrees photography in data survey and information validation stages for 'as built' modeling was analysed, comparing this technology to the traditional photography usually adopted. Based on empirical field surveys, two as built of the Fundação Nova Vida renovation process, in Florianópolis (SC), a public building dedicated to social assistance, were modeled in BIM software. With pre-renovation and post-renovation as built was possible to compare the two modalities: traditional photographs were taken in the pre-renovation stage, and 360-degrees spherical lens photographs were taken in the post-renovation stage. Parameters such as amount of contained information and size of generated photographic files were considered in the study. The 360-degrees photograph presented more available data and larger coverage area, which reduced the amount of files generated and the size of stored files. It was also verified that the traditional photograph, by not only involving the record itself, but also the decision-making about what to register, demands extra time in field surveying, while the 360-degrees photograph makes a global record. The $360-$ degrees photograph presented itself as a more effective tool if compared to the traditional photograph, allowing more agility in data verification to BIM modeling.
\end{abstract}

Keywords: 360-degrees photography. Immersive photography. As built. Renovation. BIM

How to cite this article:

GROSSKOPF, G. G.; HERDEN, Y. S.; SILVA, R. F. T.; MARCHIORI, F. F. A fotografia 360 graus como ferramenta de suporte à modelagem de "as built\&quot;. PARC Pesquisa em Arquitetura e Construção, v. 10, p. e019021, 28 maio 2019.

DOI:https://doi.org/10.20396/parc.v10i0.8653839. 


\section{Introdução}

A elaboração do as built (traduzido do inglês "como construído") é um procedimento documental utilizado tanto para registro quanto para o gerenciamento pós-ocupação de edifícios. $O$ as built apresenta informações sobre a realidade executada da obra, devendo ser fidedigno aos processos de construção realizados. Isso implica no registro de imperfeições na execução e demais divergências que existam em relação aos projetos arquitetônico, estrutural, etc. Desse modo, o as built deve representar uma construção exatamente como ela é, o que é fundamental para se ter o conhecimento detalhado de seus componentes e sistemas (KLEIN; LI; BECERIK-GERBER, 2012).

Atualmente, após um século de intensa urbanização em todo o planeta, esse documento mostra-se fundamental para a administração do que já foi construído, seja para realizar reformas, adaptações e manutenções, ou seja para planejar um projeto de gerenciamento dos sistemas operantes. Dentre as atuais ferramentas de apoio à elaboração de as built, tem-se o registro fotográfico como um dos mais significativos meios de se coletar e registrar dados em campo. Geralmente, os arquivos fotográficos funcionam como um banco de dados utilizado pelo profissional contratado para conferir e validar informações no processo de elaboração do as built.

Considerando a disseminação do sistema BIM - Building Information Modeling, traduzido como "modelagem da informação da construção" - no país (BRASIL, 2018), é possível afirmar que sua adoção na elaboração de as built apresenta elevado potencial de otimização do fluxo de trabalho. O processo BIM permite a modelagem tridimensional de edificações acrescida de informações pertinentes sobre a execução da obra, bem como a produção de documentação necessária extraída diretamente do modelo (EASTMAN et al., 2014). Contudo, para potencializar a precisão possibilitada pelo BIM, é necessário também repensar o processo de elaboração do as built, especialmente nas etapas de levantamento de dados e validação de informações.

Práticas como a observação em campo, tomada de medidas com trena e fotografias tradicionais estão sujeitas a uma série de equívocos devido à sua inerente dependência do manuseio humano, que muitas vezes é impreciso. Torna-se evidente que a repetição das mesmas práticas tradicionais de levantamento não contribui para o aprimoramento na qualidade da modelagem da informação. Para modelar um as built em BIM, acreditase que o levantamento dos dados e a validação de informações devam ser também mais completos, acurados e mais próximos da realidade.

O atual avanço tecnológico contribuiu com a construção civil no desenvolvimento de novas tecnologias que permitem a captura da realidade com aparelhos de escaneamento e fotogrametria, e também a geração de imagens virtuais imersivas com câmeras 360 graus. Essas ferramentas são capazes de aprimorar a coleta de dados em campo ao registrar os conteúdos de maneira ampla, minimizando o risco de que informações da construção deixem de ser registradas por falha humana. Desse modo, pretende-se abordar a contribuição do registro fotográfico para o processo de modelagem BIM nas etapas de levantamento de dados e validação de informações, buscando-se demonstrar que a fotografia imersiva com lente esférica 360 graus é uma ferramenta mais completa e eficaz do que a fotografia tradicional, tanto para o levantamento de dados em campo quanto para a conferência de informações.

Partindo de levantamentos que incluem fotografias tradicionais e fotografias 360 graus, foram elaborados dois as built durante o processo de reforma da Fundação Nova Vida (Figura 1), uma entidade do governo catarinense dedicada à assistência social, em Florianópolis (SC). Com os modelos tridimensionais dos as built pré-reforma e pósreforma foi possível estabelecer comparações entre os dois métodos de registro 
fotográfico adotados, considerando suas respectivas implicações no levantamento de dados em campo e na conferência de informações durante a modelagem. Foram tiradas fotografias tradicionais na etapa pré-reforma e fotografias com lente esférica 360 graus na etapa pós-reforma. Parâmetros como quantidade de informações contidas e tamanho do conjunto de arquivos de imagem foram considerados no estudo.

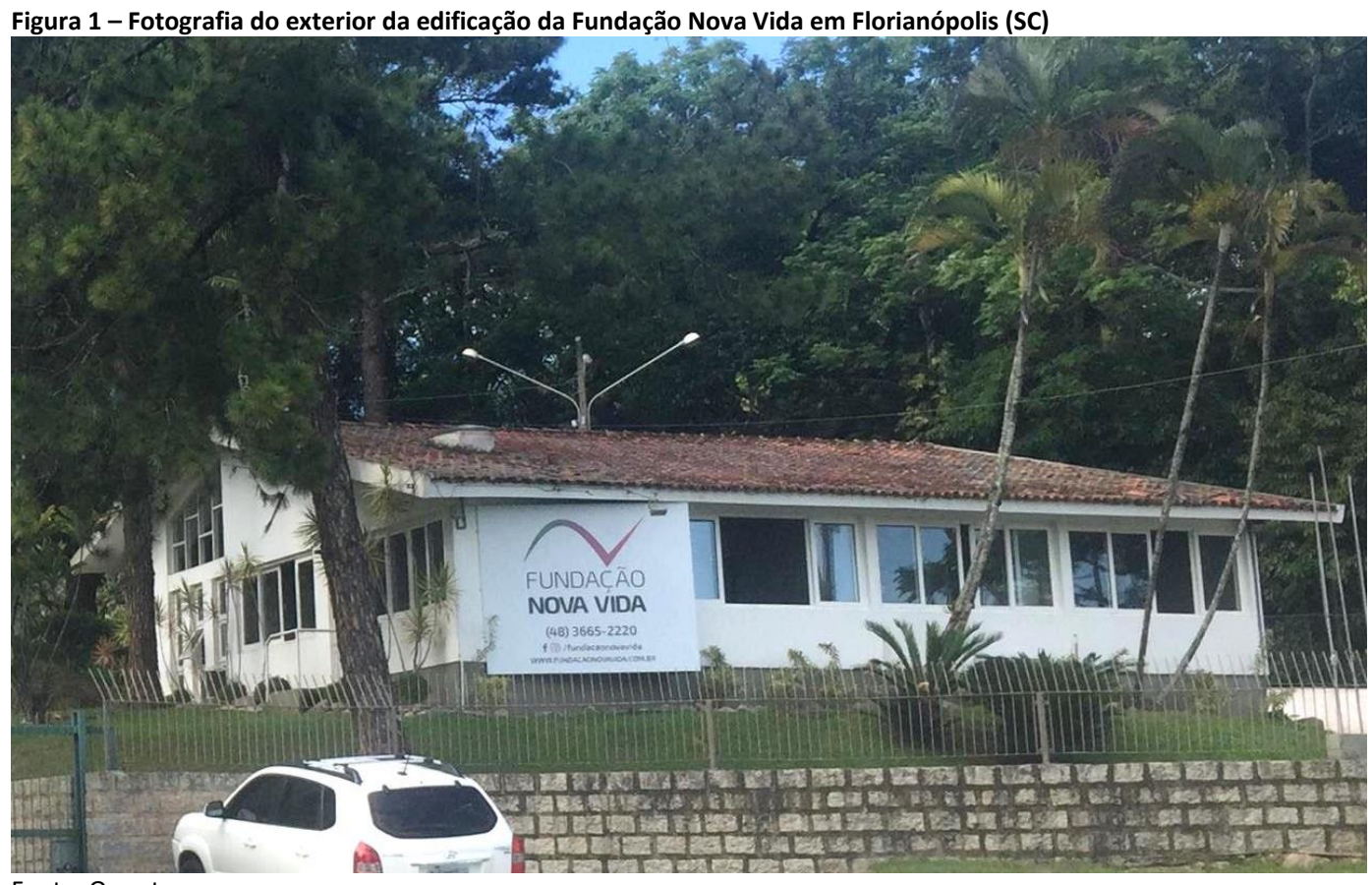

\section{Fundamentação teórica}

Indústria 4.0 - informação e imersão

Dando sequência ao processo de digitalização do mundo físico iniciado com a Terceira Revolução Industrial, o intenso avanço da tecnologia testemunhado nos últimos anos modificou estruturas de base na interação humano-máquina, introduzindo conceitos como a realidade virtual, tecnologia da informação e compartilhamento de dados. Autores como Rajkumar et al. (2010), Schwab (2016) e Coelho (2016) consideram o desdobramento de uma Quarta Revolução Industrial impulsionada pela Indústria 4.01, superando a digitalização com o desenvolvimento de sistemas ciber-físicos, ou seja, modelos que integram as dimensões real e virtual, cuja ponte é construída pela informação. O desdobramento dessas mudanças é a reformulação de práticas, processos e métodos estruturais em todas as áreas do conhecimento, como discorre Schwab (2016, p. 12, tradução própria):

A quarta revolução industrial, contudo, não é apenas sobre máquinas e sistemas inteligentes e conectados. Seu escopo é muito maior. [...] É a fusão dessas tecnologias e suas interações através dos domínios físicos, digitais e biológicos que faz da quarta revolução industrial fundamentalmente diferente das revoluções anteriores.

Mais do que oferecer ferramentas de apoio ao trabalho e à criação, a Indústria 4.0 modificou as relações entre as pessoas e o trabalho (RAJKUMAR et al., 2010; BAUER et al., 2015; COELHO, 2016; SCHWAB, 2016). Para que isso fosse possível, houve o aprimoramento de tecnologias de base capazes de proporcionar essa realidade. Nessa mudança, a informação foi um elemento chave: o trânsito de dados passou a ser 
fundamental na indústria contemporânea, atuando como a ponte entre as diferentes instâncias e instituições envolvidas em um processo decisório-produtivo.

A indústria da construção civil, apesar de ainda estar longe de alcançar os princípios da Indústria 4.0, tem tido avanços com o advento do BIM, que está modificando a prática projetual em suas instâncias mais básicas. $O$ trânsito de documentos bidimensionais de maneira hierárquica e sequencial entre diferentes profissionais da área aos poucos está sendo substituído pelo trabalho colaborativo, com o compartilhamento de dados que foram modelados tridimensionalmente, num sistema em que os componentes tridimensionais possuem uma série de informações associadas (EASTMAN et al., 2014).

Tendo em vista essas transformações, é notável o caráter imersivo nas novas tecnologias em uma tentativa de aproximação entre as dimensões real e virtual, na direção da simulação das condições reais. Na área do planejamento e da construção civil, as ferramentas de projeto aproximam-se cada vez mais da realidade de execução de uma obra e buscam compreender não só a construção mas também o ciclo de vida de um projeto. Percebe-se que a representação em convenções e códigos dá lugar à simulação de condições reais.

A reformulação das práticas, ferramentas e tecnologias de base atinge diversas esferas, incluindo também a fotografia, ferramenta amplamente utilizada pela área da construção civil. Segundo os estudos de Vicente (2005), Ramos e Laurentiz (2013), entende-se a fotografia como uma prática que reflete um contexto histórico. Desde seu surgimento até a segunda metade do século $\mathrm{XX}$, a fotografia possuía um caráter fragmentário: era um recorte temporal, um fragmento tanto em seu funcionamento quanto em sua representação. Quando o processo fotográfico se tornou digital, foi possível mesclar a imagem com novos sistemas e plataformas. No ciberespaço, seu modo de operar se transforma: a fotografia pode ser dinâmica, compartilhável, mutável e nessa transfiguração ela adquire movimento tal como a realidade (VICENTE, 2005).

No período anterior à era digital foram realizados experimentos na tentativa de se registrar o mundo de forma mais próxima à percepção humana. De acordo com Chagas Junior (2010) a ideia de imersão imagética foi iniciada com a pintura de um Panorama cilíndrico por Robert Baker em 1787. Mendonça et al. (2010) citam também como pioneiros a Câmera de Von Martens (1844), considerado o primeiro experimento de fotografia panorâmica e o Photorama dos Irmãos Lumière (1900), um equipamento que utilizava dezesseis lentes para a geração de uma imagem panorâmica cilíndrica. Em suma, dispositivos experimentais analógicos capazes de produzir imagens bidimensionais panorâmicas na busca pela imersão do espectador. Contudo, a verdadeira inflexão no modo de se interagir com a fotografia mudou com a era digital e, mais especificamente, com o conceito de ambientes virtuais imersivos.

O desenvolvimento da fotografia esférica 360 graus quebrou paradigmas da tradição fotográfica. A possibilidade de se estar em um ambiente imersivo, que simula a interação humana com a realidade, amplia a compreensão do espaço e da situação registrada, não mais sujeita a cortes. O registro da realidade em 360 graus vai além da varredura do olho humano, recriando nossa visão periférica e a consciência de que se pode ver mais ao movimentar a tela, o que intensifica a sensação de imersão naquele ambiente tal como seria se o observador estivesse lá (MENDONÇA et al., 2010; CHAGAS JUNIOR, 2010).

Por apresentar uma simulação ultrarrealista da interação sujeito-espaço, a fotografia 360 graus se mostrou como uma poderosa ferramenta para a verificação e validação de informações espaciais, com elevado potencial de utilidade para as áreas de georreferenciamento, planejamento urbano e construção civil. Esse tipo de fotografia 
produz reduzida quantidade de arquivos se comparado à fotografia tradicional, pelo fato de registrar uma grande quantidade de dados com apenas um disparo (BARAZZETTI; PREVITALI; RONCORONI, 2018).

Tendo-se em mente a potencialidade da fotografia 360 graus, supõe-se que essa ferramenta seja capaz de agilizar a validação de dados na modelagem BIM ao concentrar uma significativa gama de informações em um único arquivo e reproduzir a percepção humana de se estar no ambiente registrado. Essas características aproximariam o indivíduo de sua experiência corporal no local, facilitando sua busca por dados e a localização das informações que procura. Desse modo, além de otimizar o levantamento de dados em campo, a foto 360 seria capaz de reduzir o tempo gasto na validação de dados para a modelagem, podendo incrementar o fluxo de trabalho no sistema BIM na elaboração de um as built.

\section{Método de pesquisa}

O objeto de estudo da pesquisa é a contribuição do registro fotográfico no processo de modelagem dos as built pré-reforma e pós-reforma da edificação existente da Fundação Nova Vida. A equipe do Laboratório de BIM de Santa Catarina atendeu à solicitação de modelagem do as built dessa edificação para a realização de uma reforma interna, contando também com a posterior modelagem da obra reformada. Adotou-se o método de pesquisa empírica em campo, utilizando-se fotografias tradicionais no levantamento de dados para a elaboração do as built pré-reforma, e fotografias imersivas 360 graus na atualização do modelo pós-reforma. Desse modo, foi possível estabelecer comparações entre as distintas maneiras de registrar a realidade com fotografias, comparando parâmetros como mão de obra necessária nos levantamentos, quantidade de informações contidas e o tamanho dos conjuntos de arquivos fotográficos. Também foi possível para a equipe avaliar se a fotografia 360 graus promoveu uma maior eficácia na validação de dados do que a fotografia tradicional, abordando aspectos qualitativos referentes à conferência de dados, tais como facilidade na busca por arquivos e agilidade na identificação da informação requerida no ambiente através do registro fotográfico.

O levantamento de dados para a modelagem inicial do as built, em uma etapa préreforma, foi realizado com métodos tradicionais de levantamento em campo: medida de elementos com trena; anotações e desenhos em prancheta; fotografias digitais com lente comum via aparelhos celulares. Esses procedimentos foram realizados simultaneamente por quatro membros da equipe, que dividiram as tarefas entre si, em um período compreendido entre duas tardes de visita ao local. As medições foram feitas para identificar as dimensões e distâncias entre os elementos da construção. As fotografias foram tiradas por dois dos membros da equipe, priorizando o registro de elementos básicos da edificação (estrutura, vedações, aberturas, revestimentos), além do mobiliário existente (Figura 2).

Após o primeiro levantamento, os membros da equipe iniciaram a modelagem da edificação de forma colaborativa, no software BIM ArchiCAD. Foram modelados os elementos materiais da edificação (estrutura, paredes, aberturas, revestimentos, etc.) e o mobiliário interno, contando também com o terreno e as vias de acesso. $O$ registro fotográfico serviu como banco de dados para validar dúvidas referentes às anotações manuais, auxiliando também na identificação de mobiliário, dos tipos de revestimento e demais aspectos visuais de elementos da construção, como portas, janelas e paredes. 
GROSSKOPF, Gabriel G. et al.

A fotografia 360 graus como ferramenta de suporte à modelagem de "as built"

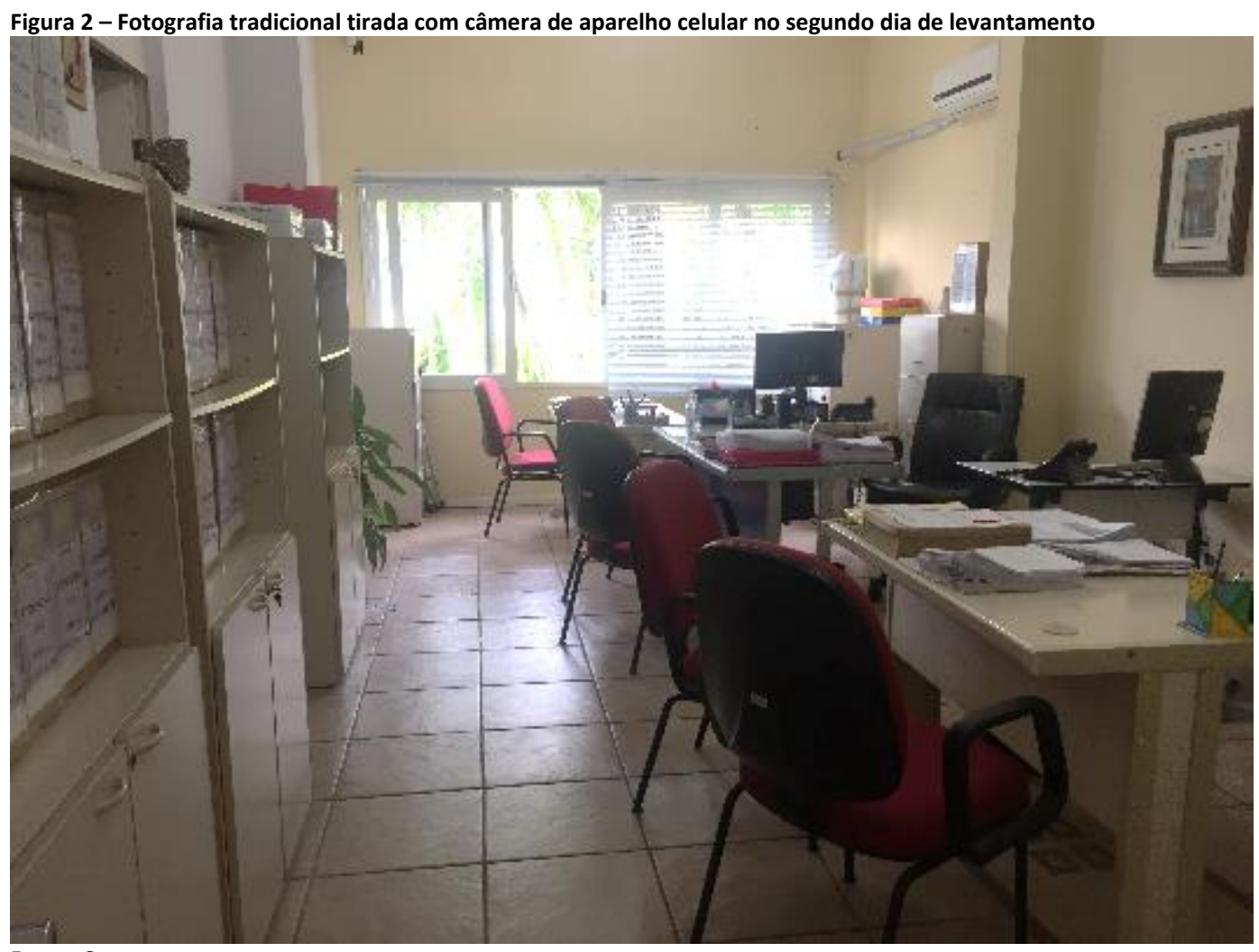

Fonte: Os autores.

Durante o processo de modelagem, com as fotografias tradicionais e anotações em mãos, identificou-se a falta de informações necessárias para a confecção de um as built que correspondesse à realidade, surgindo a necessidade de uma nova visita à edificação para conferência de medidas e um segundo levantamento fotográfico. Com o novo material foi possível finalizar a modelagem do as built pré-reforma e gerar a documentação necessária para a realização do estudo de reforma (plantas baixas, cortes, fachadas, etc.).

Os dois levantamentos iniciais diferem entre si na duração e na quantidade de pessoas envolvidas. Considerando somente o levantamento fotográfico, o primeiro dia teve duração de duas horas e onze minutos (primeira foto tirada às 14:41 e última foto às 16:52), e as fotos foram tiradas por dois membros da equipe. O levantamento do segundo dia, o qual somente um membro voltou à edificação para conferências e fotos extra, durou quarenta e nove minutos (primeira foto às 11:01 e última foto às 11:50). Portanto, foram contabilizadas, no período total de dois dias, três horas de trabalho para os registros fotográficos tradicionais.

Na reforma foram alterados os mobiliários da maior parte dos ambientes e a pintura das faces internas das paredes, contando também com a retirada de algumas divisórias e a substituição de revestimentos de piso. Considerando que a maior parte dos elementos estruturais e de vedação da edificação (estrutura, paredes externas, portas e janelas) permaneceu inalterada, a equipe utilizou o modelo anterior como referência para atualizar os elementos reformados.

Para o levantamento de dados dessas alterações, foi utilizada uma câmera de fotografias imersivas com lente esférica 360 graus Ricoh Theta V (Figura 3). Foram definidos pontos estratégicos na edificação: no mínimo um por ambiente nas salas mais utilizadas, contando com mais de um ponto nas salas em que somente uma fotografia não abrangeu a totalidade do ambiente. As fotografias foram disparadas com a câmera 
GROSSKOPF, Gabriel G. et al.

A fotografia 360 graus como ferramenta de suporte à modelagem de "as built"

sobre um tripé, mantendo o equipamento a uma altura fixa de um metro e dez centímetros do chão. Esse processo foi realizado por apenas um membro da equipe num período de duração de vinte minutos, em uma única visita ao local.

Para visualizar as fotografias 360 graus em seu modo imersivo foi utilizado o aplicativo Panorama Viewer (Figura 4), aberto em uma tela de computador enquanto a equipe trabalhava no modelo da edificação na tela adjacente. Com o uso das duas telas, foi possível atualizar o modelo de forma simultânea à verificação de dados na fotografia imersiva. Com esse fluxo de trabalho o modelo pré-reforma foi atualizado com as mudanças realizadas na Fundação Nova Vida, incluindo a retirada de divisórias de chapas de madeira, a substituição de mobiliários, a substituição dos revestimentos de piso e a nova pintura nas superfícies.

Figura 3 - Fotografia 360 graus em seu formato nativo

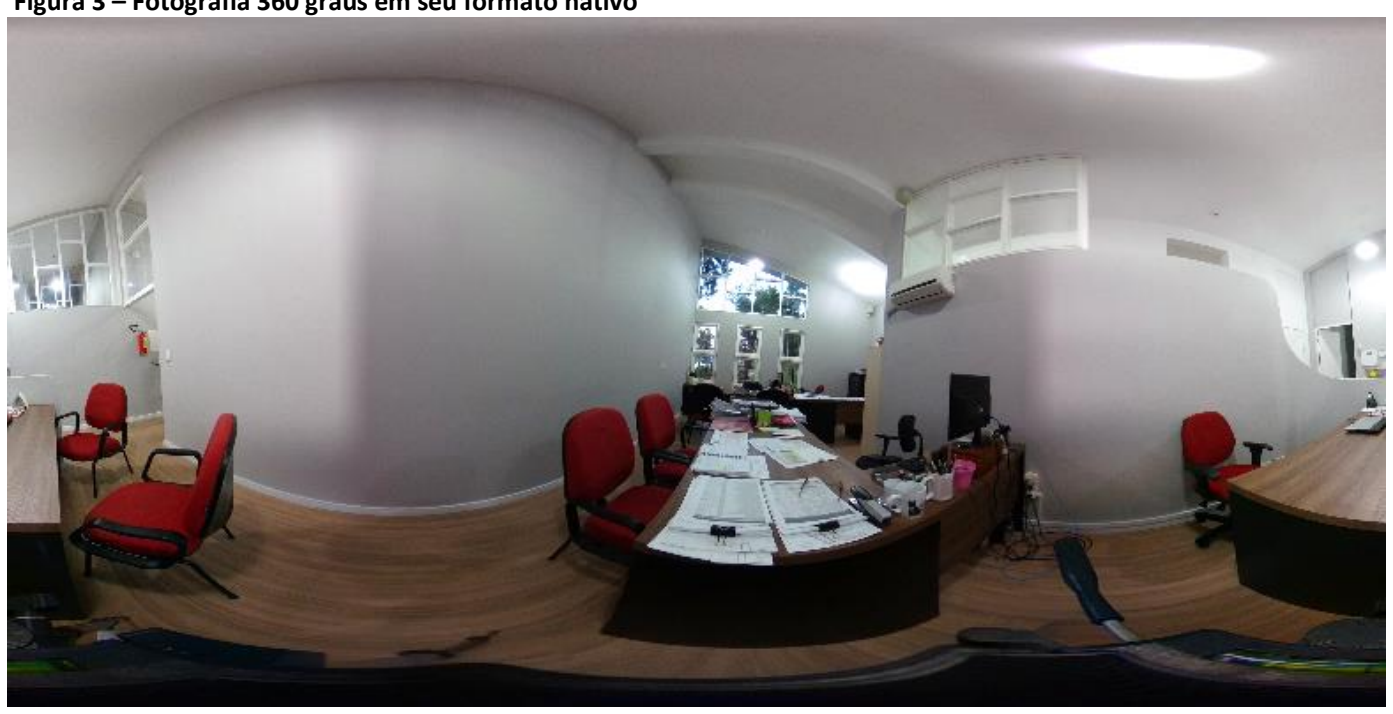

Fonte: Os autores.

Figura 4 - Fotografia 360 graus em seu formato imersivo, exibida em quatro enquadramentos de visualização diferentes no aplicativo Panorama Viewer para demonstrar seu funcionamento e abrangência
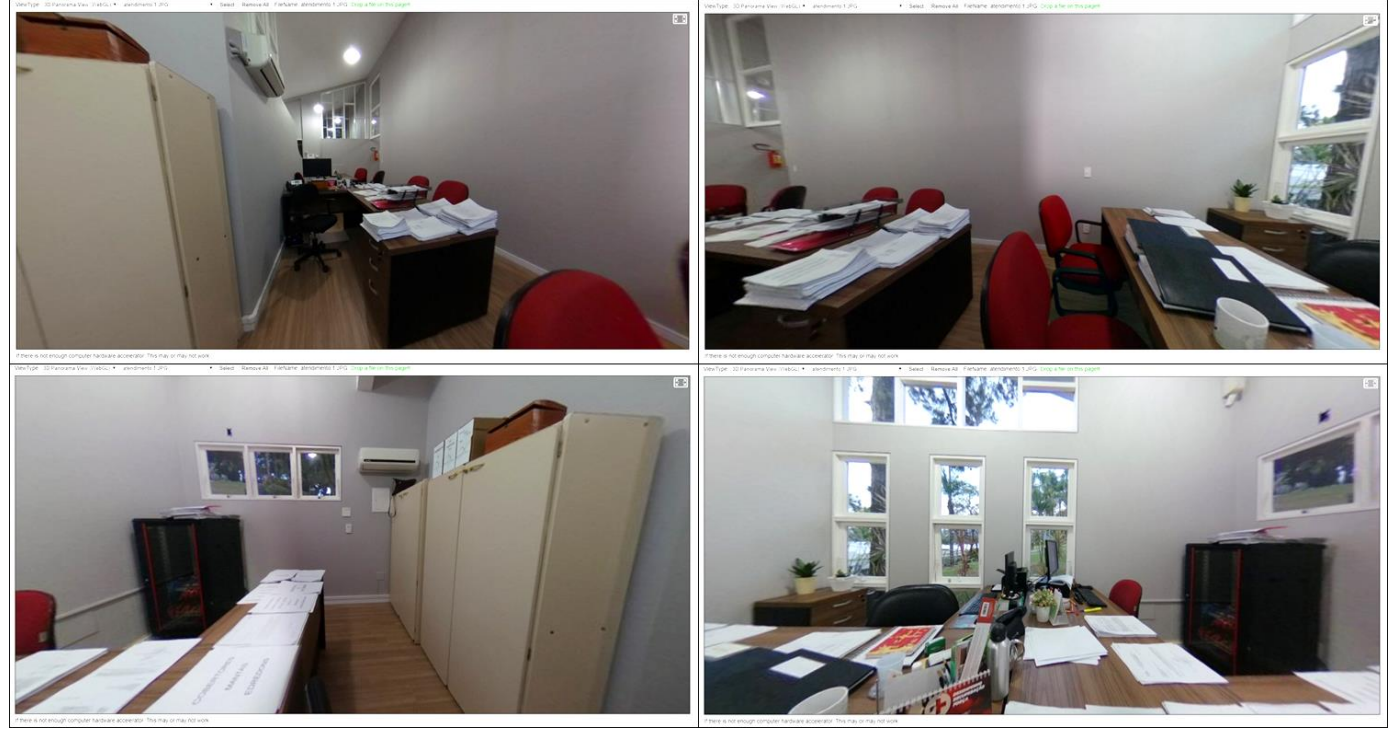

Fonte: Os autores.

Com o auxílio das fotografias 360 graus foi possível atualizar o modelo do as built conforme as mudanças realizadas, caracterizando a etapa pós-reforma, seguido pela entrega da documentação gerada pelo software BIM (Figura 5). 
Figura 5 - Fluxograma do processo de levantamento de dados e modelagem

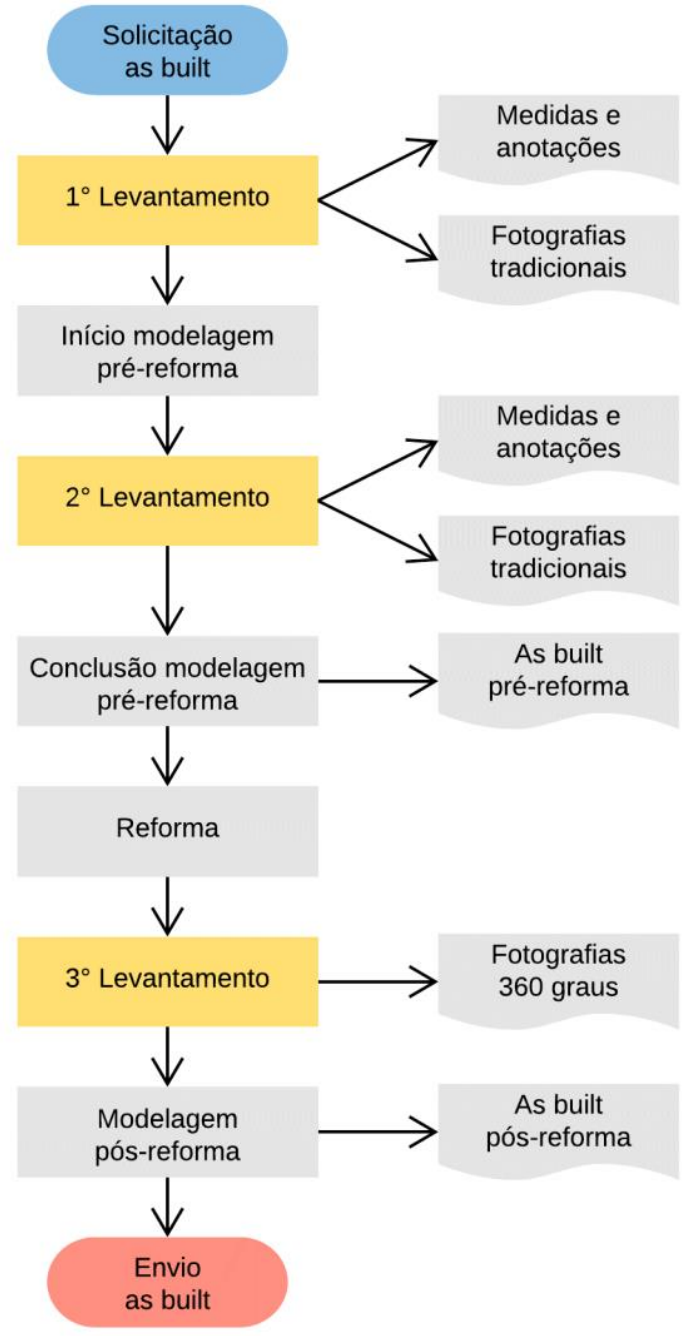

Fonte: Os autores.

Enviado o as built pós-reforma para a Fundação Nova Vida, a equipe prosseguiu o estudo no sentido de analisar os dois métodos de registro fotográfico utilizados - a fotografia tradicional e a fotografia 360 graus. Buscou-se analisar a adequabilidade de cada modalidade fotográfica à modelagem em software BIM, considerando a hipótese de que a fotografia 360 graus seria mais adequada ao fluxo de trabalho BIM por sua maior abrangência, menor produção de arquivos e caráter imersivo que reproduz mais fielmente a realidade. Nesse sentido, a fotografia 360 graus seria capaz de fornecer aos modeladores uma rica fonte de dados num registro completo do ambiente, que pode ser verificado instantaneamente. Busca-se com isso apresentar um panorama do processo fotográfico tradicional comparado ao processo realizado com câmera 360 graus, e de que maneira cada registro pode influenciar no resultado do as built, considerando a necessidade de verossimilhança do modelo com a realidade. Para comparar as modalidades fotográficas na etapa de levantamento de dados, foram adotados os seguintes parâmetros:

- Dados contidos;

- Quantidade de arquivos;

- Tamanho do conjunto de arquivos;

- Tempo registrado entre a primeira e a última foto; 
- Taxa de fotos por ambientes fotografados;

- Taxa de minutos por foto.

\section{Dados contidos}

Identifica a quantidade e qualidade de dados contidos em cada tipo de fotografia, considerando a abrangência do registro. Considera-se dado qualquer informação pertinente à elaboração do modelo capturada em fotografia, como por exemplo elementos construtivos da edificação, superfícies e mobiliários. O objetivo desse parâmetro é avaliar a capacidade de registro de cada modalidade fotográfica.

Quantidade de arquivos

Identifica a quantidade de arquivos de imagem gerados por cada modalidade fotográfica. O objetivo desse parâmetro é avaliar a eficiência de cada método de registro sob o viés da quantidade de arquivos produzidos para sua realização.

Tamanho do conjunto de arquivos

Identifica o tamanho ocupado pelo conjunto de arquivos fotográficos no armazenamento do computador, considerando a soma do tamanho de cada fotografia. O objetivo desse parâmetro consiste em avaliar a quantidade de espaço virtual ocupado por cada modalidade fotográfica, considerando o conjunto de arquivos gerados em cada levantamento em campo.

Tempo registrado entre a primeira e a última foto

Identifica o tempo total aproximado dispendido por cada modalidade fotográfica em um levantamento em campo, identificando a hora em que foram registradas a primeira e a última fotografias de cada levantamento. $O$ valor encontrado entre esses dois momentos corresponde ao tempo avaliado.

\section{Taxa de fotos por ambiente fotografado}

Parâmetro resultante da quantidade de arquivos fotográficos gerados dividida pelo número de ambientes fotografados em cada uma das modalidades. O objetivo desse parâmetro é avaliar a quantidade média de disparos realizados para se registrar cada ambiente, buscando identificar a eficiência de cada modalidade e os motivos que poderiam contribuir para esse resultado.

Taxa de minutos por foto

Parâmetro resultante da divisão do tempo total de registro pela quantidade de fotografias tiradas, para cada uma das duas modalidades fotográficas. O objetivo desse parâmetro é avaliar o tempo dispendido em cada disparo de fotografia para cada modalidade, buscando identificar a eficiência de cada método de registro e os motivos que poderiam contribuir para esse resultado.

Com os parâmetros adotados foi possível compilar os dados em quadro e estabelecer comparações entre as duas modalidades de registro fotográfico, avaliando eficiência e funcionalidade na etapa de levantamento de dados. Para comparar as duas modalidades fotográficas na etapa de validação de informações, a equipe buscou avaliá-las de modo qualitativo, abordando aspectos como a facilidade na busca por arquivos e dados e a disponibilidade de informações por fotografia. 
GROSSKOPF, Gabriel G. et al.

A fotografia 360 graus como ferramenta de suporte à modelagem de "as built"

\section{Resultados e discussão}

Os produtos do estudo foram os modelos BIM as built pré-reforma e pós-reforma da Fundação Nova Vida (Figuras 6 e 7), bem como a documentação extraída dos modelos na forma de plantas, cortes, fachadas, vistas, quadro de esquadrias (portas e janelas) e inventário de mobiliário. Nesse processo foi possível estudar duas diferentes maneiras de abordar a questão do registro fotográfico na elaboração de as built - fotografia tradicional e fotografia 360 graus - e de que modo cada uma fornece suporte à modelagem desse documento em um software BIM. Essa questão foi abordada de maneira comparativa, fazendo-se uso dos parâmetros de abrangência de captura, quantidade de membros da equipe utilizados, quantidade de arquivos produzidos, tamanho do conjunto de arquivos e tempo registrado entre o primeiro e último disparos para avalia-las na etapa de levantamento de dados. Com essas informações foi possível também estimar a produtividade de cada modalidade fotográfica pelo cálculo da quantidade média de minutos por foto.

Figura 6 - Perspectiva do modelo as built da Fundação Nova Vida com entorno imediato, elaborado em software BIM

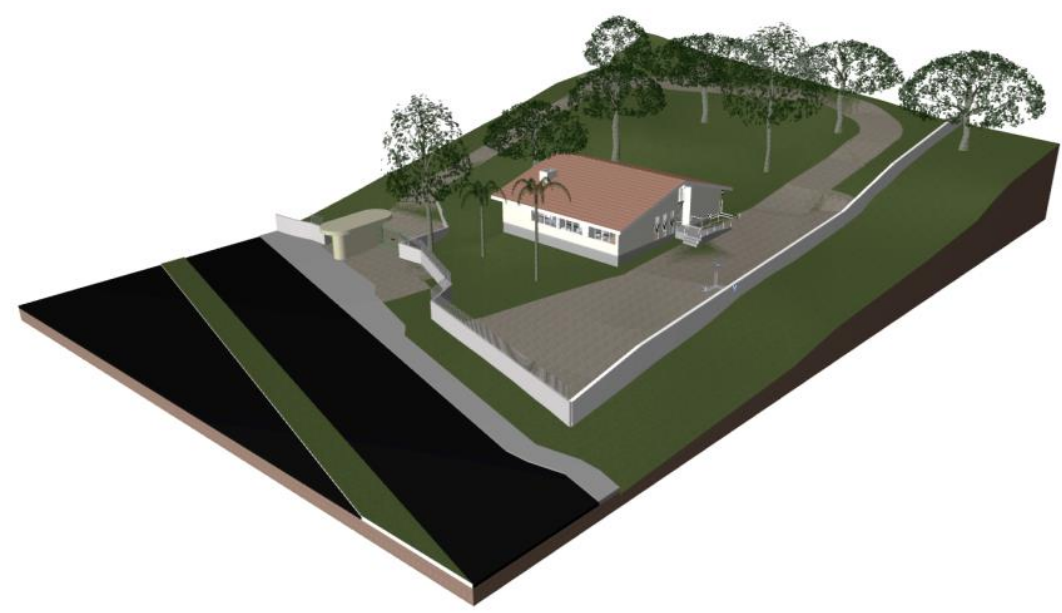

Fonte: Os autores.

Figura 7 - Perspectiva isométrica interna do modelo as built pós-reforma da Fundação Nova Vida, elaborado em software BIM. A modelagem incluiu estrutura, vedações, aberturas, mobiliários e revestimentos

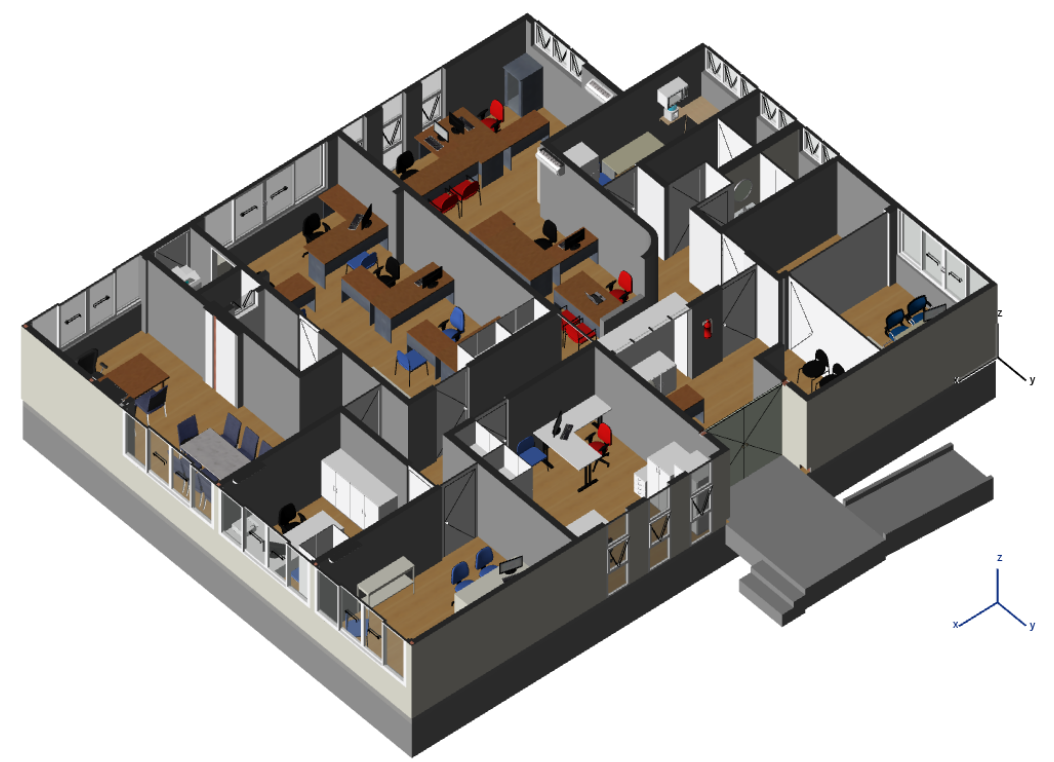

Fonte: Os autores. 
Na etapa de levantamento de dados, os registros fotográficos com câmera tradicional produziram ao final 89 arquivos, com tamanho total de 141,3 MB e foram realizados por dois membros da equipe, no primeiro dia, e um membro no segundo dia, em um tempo total de três horas (180 minutos). Os registros fotográficos com câmera esférica 360 graus, por sua vez, produziram 15 arquivos, com tamanho total de $22,7 \mathrm{MB}$, tendo sido realizado por apenas um membro da equipe num período de 20 minutos. Todos os dados estão compilados no Quadro 1.

Quadro 1 - Dados das modalidades fotográficas tradicional e 360 graus, considerando os parâmetros de avaliação

\begin{tabular}{|c|c|c|}
\hline & Fotografia tradicional & Fotografia 360 graus \\
\hline Dados contidos & $\begin{array}{l}\text { Somente o que foi capturado } \\
\text { pelo enquadramento da lente }\end{array}$ & $\begin{array}{l}\text { Tudo que estava ao alcance do } \\
\text { registro da lente esférica } 360 \text { graus }\end{array}$ \\
\hline Quantidade de arquivos & $\begin{array}{l}\text { Dia 1: } 51 \text { fotos } \\
\text { Dia 2: } 38 \text { fotos } \\
\text { Total: } 89 \text { fotos }\end{array}$ & $\begin{array}{l}\text { Dia 1/Total: } \\
15 \text { fotos }\end{array}$ \\
\hline Tamanho do conjunto de arquivos & $\begin{array}{c}\text { Dia 1: 83,9 MB } \\
\text { Dia 2: 57,4 MB } \\
\text { Total: } 141,3 \mathrm{MB}\end{array}$ & $\begin{array}{l}\text { Dia 1/Total: } \\
22,7 \mathrm{MB}\end{array}$ \\
\hline Tempo registrado entre a primeira e a última foto & $\begin{array}{l}\text { Dia 1: } 131 \mathrm{~min} \\
\text { Dia 2: } 49 \mathrm{~min} \\
\text { Total: } 180 \mathrm{~min}\end{array}$ & $\begin{array}{l}\text { Dia 1/Total: } \\
20 \mathrm{~min}\end{array}$ \\
\hline Taxa de fotos por ambientes fotografados & 8,9 fotos por ambiente & 1,15 fotos por ambiente \\
\hline Taxa de minutos por foto & $\begin{array}{l}2,02 \text { minutos } \\
\text { por foto }\end{array}$ & $\begin{array}{l}1,33 \text { minutos } \\
\text { por foto }\end{array}$ \\
\hline
\end{tabular}

Nas plantas baixas (Figuras 8 e 9) são mostrados os pontos de onde foram tiradas as fotografias. Na Figura 8, é possível visualizar todos os pontos das fotografias tradicionais, em azul, incluindo o direcionamento da foto e a abrangência estimada representados em amarelo. Na Figura 9, é possível visualizar todos os pontos das fotografias 360 graus, representados por um círculo rosa indicando sua abrangência.

$\mathrm{Na}$ planta dos pontos fotográficos tradicionais (Figura 8), nota-se pelas formas em amarelo a sobreposição de diversos registros em termos de abrangência, situação recorrente nesse estudo. A fotografia tradicional não foi capaz de registrar amplamente um espaço reduzido, resultando na necessidade de se realizar pelo menos mais de um registro por ambiente e gerando, consequentemente, diversos arquivos fotográficos. Na planta dos pontos fotográficos 360 graus (Figura 9), nota-se que foi necessária de uma a duas capturas em cada ambiente, uma proporção significativamente reduzida em comparação à quantidade de registros tradicionais.

As duas modalidades de registro fotográfico possuem diferentes modos de operação. A fotografia tradicional possui captura fragmentária e, desse modo, exige que seja tirada uma quantidade significativa de fotografias para o entendimento de um espaço. A fotografia imersiva 360 graus possui captura integral, sendo capaz de registrar espaços integralmente com apenas um disparo. Há também uma significativa diferença na quantidade de arquivos produzidos e, consequentemente, no tamanho de arquivos armazenados em máquina.

Com esses dados foi possível calcular a taxa média de fotografias tiradas por ambiente fotografado para cada modalidade. Com a fotografia tradicional, obteve-se o valor médio de 8,9 fotos por ambiente, considerando-se um total de 89 fotos divididas para 10 ambientes registrados dos 16 . Com a fotografia 360 graus, obteve-se o valor médio de 1,15 fotos por ambiente, considerando-se um total de 15 fotos divididas para 13 ambientes registrados dos 15 pós-reforma. A diferença entre a quantidade de arquivos 
GROSSKOPF, Gabriel G. et al.

A fotografia 360 graus como ferramenta de suporte à modelagem de "as built"

nas duas modalidades é significativa, especialmente se considerar que a captura da foto 360 graus é capaz de registrar um ambiente em sua totalidade. Figura 8 - Planta baixa da edificação no momento pré-reforma, extraída do modelo BIM, com o mapeamento dos
registros fotográficos tradicionais

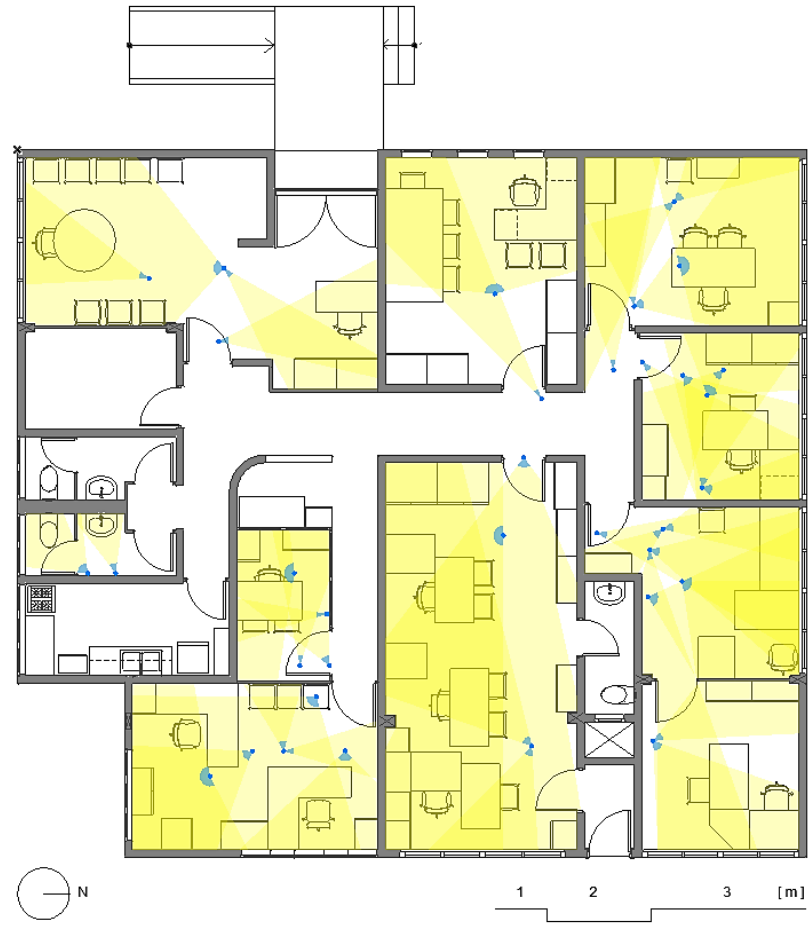

Fonte: Os autores.

Figura 9 - Planta baixa da edificação no momento pós-reforma, extraída do modelo BIM, com o mapeamento dos registros fotográficos 360 graus.

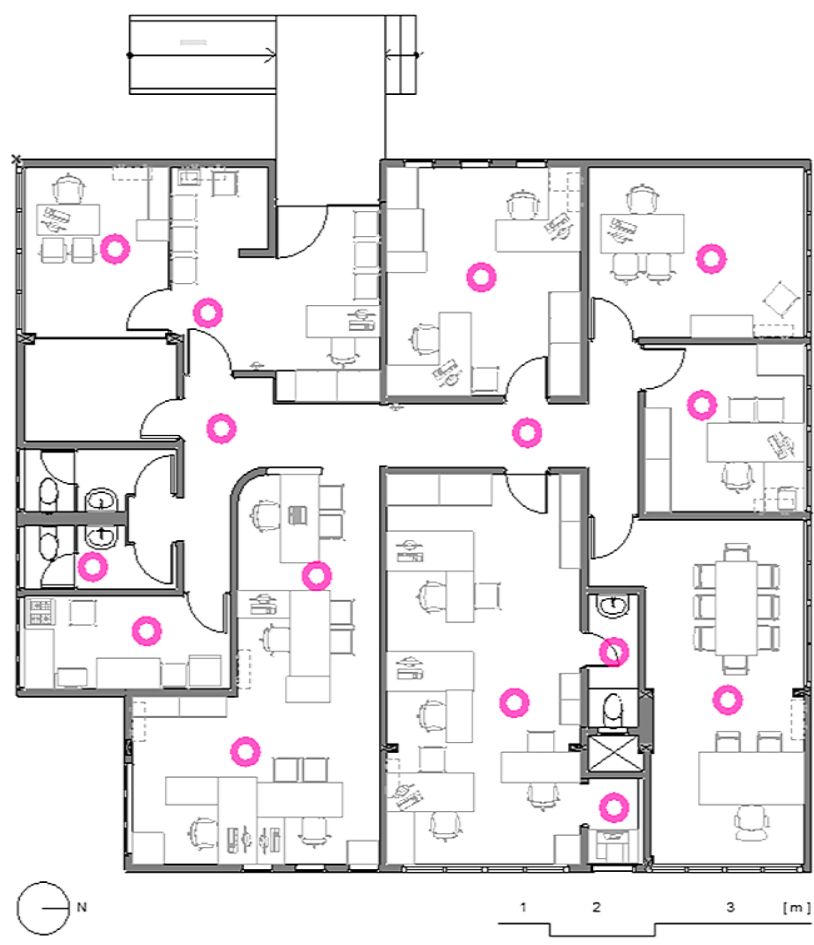

Fonte: Os autores. 
Outro fator de grande relevância foi o tempo de operação nas duas modalidades: nas fotografias tradicionais foi calculado o tempo total de 180 minutos ( 3 horas) entre a primeira e a última fotografia, considerando-se os dois dias de visita; nas fotografias 360 graus, foi calculado o tempo total de 20 minutos entre a primeira e a última fotografia. Identificou-se que um dos fatores que demanda tempo na fotografia tradicional é a tomada de decisão sobre o que registrar, de que ângulo, posição, etc. Essa tomada de decisão é realizada para cada fotografia, o que aumenta o tempo de trabalho em função do tamanho e complexidade dos espaços que serão registrados.

Considerando-se os dados apresentados sobre quantidade de arquivos produzidos e tempo de operação foi possível calcular a taxa de produtividade considerando fotografias por minuto. Com a modalidade de fotografia tradicional, obteve-se uma taxa média de 2,02 minutos por foto. Na modalidade de fotografia imersiva esférica 360 graus, obteve-se uma taxa de 1,33 minutos por foto. Comparando-se a taxa de minutos por fotos entre as duas modalidades, nota-se que a da câmera 360 graus é menor pelo reduzido tempo necessário à tomada de decisão. Pode-se afirmar com isso que o levantamento de dados com a fotografia 360 graus é praticamente duas vezes mais ágil se comparado à fotografia tradicional.

Tratando-se da etapa de validação de dados por registro fotográfico, a equipe verificou uma maior facilidade na busca por arquivos na modalidade 360 graus se comparada à fotografia tradicional, haja vista que a média de fotos por ambiente é de 1,15 para essa modalidade, enquanto a média de fotos por ambiente para a foto tradicional é de 8,9 fotos por ambiente. Sendo assim, a quantidade de arquivos para ser verificada é muito menor na modalidade 360 graus. O processo de busca por informação espacial mostrouse muito mais ágil na foto 360 graus à medida em que ela reproduz a experiência humana no espaço pela imersão, aproximando a experiência virtual da experiência concreta. Na fotografia tradicional, muitas vezes é necessário alternar entre dois registros ou mais para se buscar uma mesma informação que, numa situação crítica, pode nem estar contida nos registros por fatores como esquecimento dos operadores ou incapacidade de captura da lente utilizada. A modalidade 360 graus realiza a captura integral do entorno próximo, reduzindo a necessidade de se alternar arquivos para verificar dados de um mesmo ambiente.

\section{Conclusão}

Considerando-se os parâmetros de abrangência de captura, quantidade de arquivos produzidos, tamanho do conjunto de arquivos e tempo registrado entre o primeiro e último disparos, foi possível estabelecer comparações entre as modalidades de fotografia tradicional e fotografia imersiva 360 graus na etapa de levantamento de dados. Também foi possível avaliar se a fotografia 360 graus é mais eficaz na validação de dados durante a modelagem do as built se comparada à modalidade tradicional.

Tendo-se em mente a modelagem BIM, foi possível concluir que a fotografia 360 graus otimizou o levantamento de dados em campo se comparada à fotografia tradicional, por apresentar maior abrangência de captura, redução na quantidade necessária de registros, redução no tempo gasto em levantamento em campo e minimização do conjunto de arquivos de imagem armazenados em rede. A fotografia tradicional mostrou-se fragmentária, exigindo uma quantidade elevada de capturas para o registro satisfatório de um ambiente (média de 8,9 fotos por ambiente), contando com a participação de dois membros. A fotografia 360 graus mostrou-se capaz de registrar ambientes por completo com menor quantidade de capturas (média de 1,15 fotos por ambiente) e contando com apenas um membro da equipe. Essa modalidade é capaz de minimizar o risco de eventuais falhas humanas por registrar integralmente os espaços, 
reduzindo a probabilidade de que algum elemento da construção não seja registrado. Nessa mesma modalidade, a quantidade de arquivos produzida (15) e o espaço de armazenamento demandado (22,7 MB) mostraram-se consideravelmente menores do que os valores da fotografia tradicional, que produziu 89 arquivos e demandou espaço de 141,3 MB.

Embora seja necessário um planejamento prévio para decidir sobre o ponto adequado de cada disparo, a fotografia 360 graus reduz o tempo de tomadas de decisão no local devido à captura de ampla abrangência, diferentemente da fotografia tradicional. Essa diferença torna-se evidente ao comparar as taxas calculadas de 1,33 minutos por foto para 15 fotos em 20 minutos de trabalho (foto 360 graus) e 2,02 minutos por foto para 89 fotos em 180 minutos de trabalho (foto tradicional).

$\mathrm{Na}$ alimentação do modelo BIM, a fotografia 360 graus mostrou-se uma ferramenta mais eficaz se comparada à fotografia tradicional, proporcionando maior agilidade na conferência de dados. Como a modalidade tradicional exige maior quantidade de fotografias para registrar um ambiente, torna-se necessário alternar entre mais de um arquivo para verificar informações desse espaço, enquanto a foto 360 graus é capaz de agilizar a conferência e validação de dados por sua reduzida quantidade de arquivos.

Considerando-se os benefícios apresentados sobre o uso de fotografias imersivas 360 graus no levantamento e validação de dados para a modelagem BIM de as built, esperase ampliar o conhecimento sobre o tema e demonstrar a adequabilidade dessa ferramenta ao fluxo de trabalho no sistema BIM. A foto 360 não elimina a necessidade de extração de medidas e visitas a campo, mas mostrou-se como uma poderosa ferramenta de suporte à elaboração de as built, otimizada em funcionamento em relação à fotografia tradicional, que é a ferramenta comumente utilizada nesses casos.

Assim como o BIM potencializa a colaboração e a informação no processo de projeto, o caráter imersivo das fotos 360 simula a realidade de forma verossímil, alinhado com os rumos identificados na Indústria 4.0, como a simulação do real, a otimização do fluxo de trabalho e a informação como elemento-chave. Com esse estudo, busca-se exemplificar uma das diversas aplicações da fotografia 360 graus, como por exemplo em vistorias, fiscalizações e monitoramento de obras.

\section{Notas}

(1) Indústria 4.0 é um termo cunhado em 2011 na Feira Internacional de Hannover, Alemanha, para definir a substituição do conceito de produção em massa pela ideia de customização em massa que, segundo Wilheim Bauer et al (2015) e Pedro Coelho (2016), consiste no atendimento a desejos específicos e individuais a custos reduzidos.

\section{Referências}

BARAZZETTI, Luigi; PREVITALI, Mattia; RONCORONI, Fabio. Can we use low-cost 360 degree cameras to create accurate 3D models? In: MID-TERM SYMPOSIUM OF THE INTERNATIONAL SOCIETY OF PHOTOGRAMMETRY, REMOTE SENSING AND SPACTIAL INFORMATION SCIENCE, 2., 2018, Riva del Garda. Annals [... ]. Riva del Garda: ISPRS, 2018, Vol. XLII-2. p. 69-75. DOI:https://doi.org/10.5194/isprs-archives-XLII-2-69-2018

BAUER, Wilhelm et al. Transforming to a hyper-connected society and economy - towards an "industry 4.0". Procedia Manufacturing. Holanda, v. 3, p. 417 - 424. 2015. DOI: https://doi.org/10.1016/j.promfg.2015.07.200

BRASIL. Decreto n. 9.377, de 17 de maio de 2018. Institui a Estratégia de Disseminação do Building Information Modelling. Lex: Diário Oficial da União, Brasília, Edição 95, Seção 1, p. 3. ISSN 1677-7042. 
GROSSKOPF, Gabriel G. et al.

A fotografia 360 graus como ferramenta de suporte à modelagem de "as built"

CHAGAS JUNIOR, Edson das. Fotografia panorâmica multimídia: de Robert Barker ao fotógrafo panoramista investigando a práxis do dispositivo. In: CONGRESSO DE CIÊNCIAS DA COMUNICAÇÃO NA REGIÃO SUDESTE, Vitória, 15., 2010, São Paulo. Anais [...]. São Paulo: Intercom, 2010.

COELHO, Pedro M. N. Rumo à indústria 4.0. 2016. 62 p. Dissertação (Mestrado em Engenharia e Gestão Industrial) Departamento de Engenharia Mecânica, Faculdade de Ciências e Tecnologia, Universidade de Coimbra, Portugal, 2016.

EASTMAN, Charles M. et al. Manual de BIM - um guia de modelagem da informação da construção para arquitetos, engenheiros, gerentes, construtores e incorporadores. Tradução: Cervantes Gonçalves Alves Filho et al. Porto Alegre: Bookman, 2014.

KLEIN, Laura; LI, Nan; BECERIK-GERBER, Burcin. Imaged-based verification of as built documentation of operational buildings. Automation in Construction, Holanda, n. 21, p. 161-171, jan. 2012. DOI:

https://doi.org/10.1016/j.autcon.2011.05.023

MENDONÇA, André N. F. et al. Fotografia panorâmica e sua relação homem-técnica. Informática na educação: teoria e prática, Porto Alegre, v.13, n.2, p. 102 - 111, jul./dez. 2010.

RAJKUMAR, Ragunathan et al. Cyber-physical systems: the next computing revolution. In: DESIGN AUTOMATION CONFERENCE, 47., 2010, Anaheim. Proceedings [... ]. Nova York: ACM, p. 731-736, 2010. DOI: https://doi.org/10.1145/1837274.1837461

RAMOS, Matheus M.; LAURENTIZ, Silvia. Crise sistêmica: um novo olhar sobre a fotografia. Discursos fotográficos. Londrina, v.9, n. 14, p. 55 - 70, 2013. DOI: http://dx.doi.org/10.5433/1984-7939.2013v9n14p55

SCHWAB, Klaus. The fourth industrial revolution. Suíça: World Economic Forum, 2016.

VICENTE, Carlos F. Fotografia: a questão eletrônica. In: SAMAIN, Etienne (org.). O fotográfico. São Paulo: Huitec/Senac, p.319-328. 2005.

\section{${ }^{1}$ Gabriel George Grosskopf}

Aluno de graduação do curso de Arquitetura e Urbanismo (UFSC). Estagiário no Laboratório BIM de Santa Catarina. Endereço postal: Campus Reitor João David Ferreira Lima, Trindade, Florianópolis, SC, Brasil, CEP: 88040-900.

\section{${ }^{2}$ Yasmin Sarquis Herden}

Aluna de graduação do curso de Arquitetura e Urbanismo (UFSC). Estagiária no Laboratório BIM de Santa Catarina. Endereço postal: Campus Reitor João David Ferreira Lima, Trindade, Florianópolis, SC, Brasil, CEP: 88040-900.

\section{Rafael Fernandes Teixeira Silva}

Engenheiro de Produção Civil (UFSC) e Engenheiro de Materiais (UFSC). Especialista em Direito Ambiental e Urbanismo. Coordenador do Laboratório BIM de Santa Catarina na Secretaria de Estado do Planejamento. Endereço postal: Rodovia SC 401, km 5, 4.600 - Centro Administrativo - Bloco 3 - $2^{\circ}$ andar - Saco Grande, Florianópolis, SC, Brasil, 88032-000.

\section{Fernanda Fernandes Marchiori}

Engenheira Civil (UFSM). Doutora em Engenharia de Construção Civil e Urbana (USP). Professora do Departamento de Engenharia Civil da Universidade Federal de Santa Catarina. Endereço postal: Campus Reitor João David Ferreira Lima, Trindade, Florianópolis, SC, Brasil, CEP: 88040-900. 